\title{
Obstetric and Perinatal Outcomes of Teenage Pregnancies: A Cross-Sectional Study
}

\author{
Ahamed Lebbe Failur Rahman1, Athambawa Mohamed Razmy², \\ Mohammed Muzammil Al-Ameen Rizath' \\ ${ }^{1}$ Ashraff Memorial Hospital, Kalmunai, Sri Lanka \\ ${ }^{2}$ Department of Mathematics \& Statistics, Sultan Qaboos University, Muscat, Oman \\ Email: mrazmy@squ.edu.om
}

How to cite this paper: Rahman, A.L.F., Razmy, A.M. and Rizath, M.M.A.-A. (2017) Obstetric and Perinatal Outcomes of Teenage Pregnancies: A Cross-Sectional Study. Open Access Library Journal, 4: e3839. https://doi.org/10.4236/oalib.1103839

Received: July 21, 2017

Accepted: September 16, 2017

Published: September 19, 2017

Copyright $\odot 2017$ by authors and Open Access Library Inc.

This work is licensed under the Creative Commons Attribution International License (CC BY 4.0).

http://creativecommons.org/licenses/by/4.0/ c) (i) Open Access

\begin{abstract}
The teenage pregnancy is still preferred in different part of the world against the advice of the medical practitioners. This study aimed to describe the obstetric and perinatal outcomes of the teenage mothers and to compare these with outcomes of the adult mothers. For this purpose, 762 teenage and 756 adult mothers were followed in the eastern region of Sri Lanka for 21 months. This study found that the premature birth was the only negative perinatal outcome directly related to teenage mothers. All other negative pregnancy outcomes associated with teenage pregnancy were caused by the factors which are prevailing in higher percentages among teenagers such as low BMI and less number of parity. No differences in occurrence of small to date (IUGR), perinatal complications and lower segment caesarean section (LSCS) were observed between teenage and adult mothers. Finally, this study concludes the teenage pregnancy can be accepted for the mothers with higher BMI if the risk for premature birth is controlled.
\end{abstract}

\section{Subject Areas}

Health Policy

\section{Keywords}

Adult Mothers, Low Birth Weight, Prematurity, Teenage Mothers

\section{Introduction}

Teenage pregnancy is defined as a teenage girl, usually within the ages of $13-19$, becoming pregnant [1]. Teenage pregnancy can crop up in both married and unmarried girls. Among the married girls, this can be planned or unplanned. The unplanned pregnancy in married may be due to contraceptive failure or 
unmet need. Teenage pregnancy in unmarried may be due to unprotected sexual intercourse, contraceptive failure and sexual abuse. Socio-economic factors associated with these two categories are significantly different. It may create significant differences in the outcomes of the pregnancies too.

Globally there were 16 million births yearly to young married and unmarried women aged 15 - 19 years, representing 11\% of all births worldwide [1]. Among this, $10 \%$ to $40 \%$ are unintended among the young unmarried girls [2]. About $95 \%$ of these births to the teen age mothers occurred in developing countries where as $49 \%$ of girls in these countries get married before the age of 18 years. But the good news is that $90 \%$ of adolescent pregnancies in the developing world are among the girls who are already married [3]. In these countries, once girls are married, their husbands and in-laws, typically encourage early pregnancy.

Among the developed countries, USA has the highest percentage of teenage pregnancy and it was accounted for $7.8 \%$ of all births in 2012 [4]. Unlike the developing countries, approximately $82 \%$ of teenage pregnancies are unintended in the USA and for majority of the unmarried women. The socio-economic consequences might be more severe on the outcome teenage pregnancy for the unmarried women.

Teenage pregnancy earns the public health attention, because of its biological and the socioeconomic consequences. It has been observed, reduction in age at menarche and change in social and cultural norms regard to sexual relationships, on top of use of drugs and alcohol leads to the increase of premarital intercourse in developed and developing world. These changing biological and social environments have an influence on the trend, prevalence and the outcome of teenage pregnancies. Furthermore, the persisting practices of teenage marriage in various parts of the world also contribute to the problem to persist in various levels.

Many studies have shown that negative pregnancy outcome is significantly higher in teenagers than the adults. Infants of teen mothers are more likely to be premature and experience infant mortality. The children of teenage mothers do less well on indicators of health and social wellbeing than do children of older mothers [5] [6]. Complications from pregnancy and childbirth are the leading cause of death in young women aged 15 to 19 in developing countries and an estimated 70,000 adolescent mothers die each year because they have children before they are physically ready for parenthood [1]. The teenage mothers have to compromise the nutrition for their physical development and the development of their foetus. Meanwhile, the immature reproductive system of teenagers will not offer the adequate support and accommodation to the rapidly growing foetus. In addition to the above, impulse control, planning, and decision-makings are mostly the function of the frontal cortex; that is still maturing during adolescence. Therefore, the ability for the brain to plan, adapt to the social environment and to imagine possible future consequences of action or to appropriately gauge their emotional significance are still developing throughout adolescence. 
Numerous studies found, the preterm birth rate is significantly high among teenagers mothers [7] [8] [9]. On the other hand, the mode of delivery showed that different findings depend on the location of the study. Dias et al. (2013) found that the normal vaginal deliveries are significantly higher and the LSCS rate is significantly lower in the teenage group than the adult group [7]. Conversely Goonewardene \& Deeyagaha (2005) found there was no different in the mode of delivery between teenager and adult groups [9]. This variation in the finding may be attributable to the age and parity different in the control groups in both studies.

In a study by Dutta and Joshi (2013), it was found the Low birth weight (LBW) was significantly more for the teenage mothers (29.2\%) compared to the adult mothers (16.6\%). Also, birth asphyxia was found in $29.2 \%$ of the neonates of the teenage mothers and $7.3 \%$ of the neonates of the adult mothers [10]. These negative outcomes may be the consequence of the higher rate of preterm delivery in the teenage group.

Meanwhile some studies found that good quality prenatal and natal care will reduce the negative pregnancy outcome in teenagers [11]. A large Canadian cohort study confirms that, compared with adults, adolescents have improved outcomes such as lower rates of gestational hypertension, gestational diabetes, antepartum hemorrhage and operative deliveries [12].

Although the negative consequences of teenage pregnancies were established in many studies, still it is difficult to establish how far the biological factor related to age contributes in the physical outcome such as birth weight, prematurity and other perinatal complications. A WHO multi-country survey across the 29 countries in Africa, Asia, Latin America and the Middle East demonstrated the prevalence of adverse pregnancy outcomes varied by country among adolescents versus adult mothers [13]. In this view, a cross-sectional study was conducted for describing the characteristics and outcomes of pregnant teenagers and comparing the obstetric and perinatal outcome of the teenage pregnant mothers with the adult mothers by following 762 teenage mothers and 756 adult mothers for a period of 21 months in Sri Lanka.

\section{Methodology}

This study was conducted in the Batticaloa district of Sri Lanka. For this prospective study all the 762 teenage mothers who gave single birth during the period of 21 months, from January 2014 to September 2015 were followed for the pregnancy outcomes and related factors. For comparison purpose, another 756 adult mothers (roughly equal number of the teenage mothers) who gave single birth during this period were randomly selected and followed. The recorded variables for each mother were birth weight of baby, status of prematurity and IUGR, perinatal complications, level of education, occupation, family income, height, weight, hemoglobin level, parity, mode of delivery and gestational duration. The mothers with multiple pregnancies and incomplete records were ex- 
cluded from the study. The noted perinatal complications were placenta praevia, eclampsia, abnormal presentation, delay in labour, Asphyxia related complications, birth abnormality and postpartum psychosis.

Ethical clearance for this study was obtained from the ethics review committee of the Faculty of Medicine, University of Colombo, Sri Lanka. A pilot study was conducted with 20 mothers in another health region before starting the study. Public health midwifes in the relevant regions had been trained on extracting data from available records using a data extraction sheet prepared by the investigator. Epi-Data 3.1 software was used for data entry. The statistical analysis was carried out using Statistical package for Social Science (SPSS) Version 16.

\section{Results and Discussion}

Table 1 summarizes the comparisons of the statistics for birth weight, prevalence of LBW, BMI, Haemogloboin level, family income and education level for the teenage and adult mothers.

The mean birth weight of the babies of teenage and adult mothers was $2.80 \mathrm{~kg}$ and $2.96 \mathrm{~kg}$ respectively. Although these two mean birth weights are above the cutoff for the LBW, the mean birth weight for the babies of the teenage mothers is significantly less than the babies of adult mothers $(\mathrm{p}<0.001)$. The percentage of LBW among the sample was found to be $13.5 \%$ (95\% CI, $12.0 \%$. 15.0\%) where as it was $17 \%$ and $10 \%$ for teenage and adult pregnant mothers respectively. The teenage mother had 1.76 times higher chance of having LBW compare to the adult mother (95\% CI, 1.36, 2.29). Overall $31.1 \%$ of the pregnant mothers had the low BMI of less than 18.5 at the beginning of the pregnancy (on or before 12 weeks of POA). The binary logistic regression reveals that the teenage mothers had 2.71 times higher chance for being a low BMI mother compared to the adult mothers (95\% CI, 2.21, 3.33). No significant difference in the mean haemoglobin levels was found between the adult $(11.7 \mathrm{~g} / \mathrm{dL})$ and the teenage mothers $(11.6$ $\mathrm{g} / \mathrm{dL})(\mathrm{p}=0.068)$. An association was found between the education level and teenage pregnancy $(\mathrm{p}<0.001)$ where $84 \%$ adult mothers were educated above the primary level but it was $91 \%$ for the teenage mothers. This difference might be due to increase in education among the young generation. However,

Table 1. Comparison of selected Statistics between teenage and adult mothers.

\begin{tabular}{ccc}
\hline Parameter & Teenage Mothers & Adult Mothers \\
\hline Mean birth weight of the babies & $2.80 \mathrm{~kg}$ & $2.96 \mathrm{~kg}$ \\
Percentage of LBW & $17 \%$ & $10 \%$ \\
$\begin{array}{c}\text { Percentage of Mothers with BMI < 18.5 at the } \\
\text { beginning of the pregnancy }\end{array}$ & $43 \%$ & $22 \%$ \\
$\begin{array}{c}\text { Mean Haemogloboin level (g/dL) } \\
\text { mothers educated above the primary level }\end{array}$ & 11.6 & 11.7 \\
Average family income (SLR.) & $84 \%$ & $91 \%$ \\
\end{tabular}


the school dropout at grade 10 was higher among the teenage mothers and it is understandable. Due to this school dropout, all the teenage mothers were house wives. Therefore, the family has to depend only on the income of husband's. In this study, $31 \%$ of the adult mother's husband had regular job and this figure was $19 \%$ for the teenage mothers. The monthly average family income for the teenage mothers was SLR. 14,570.00 and for adult mothers it was SLR. 16,977.00. This shows that the socio economic condition is significantly less for the teenage mothers $(\mathrm{p}<0.001)$.This study contained two ethnic groups Tamil and Muslim, and no association in the teenage pregnancy was found between these two ethnic groups ( $p=0.349)$. With use of statistics discussed in Table 1 , one can conclude the teenage of pregnancy is a significant reason for obtaining more negative outcome in the pregnancy.

This apparent significant difference discussed above between teenage and adult mothers in the LBW cannot be attributable to age only because some biological and socio economic factors were not controlled while doing these analyses. Therefore, a multiple logistic regression was performed between dichotomized birth weight group as a dependent variable and the age group with the selected factors and the result is given in Table 2. The test revealed that the teenage mother had only 1.3 times higher chance of delivering LBW baby than an adult mother while controlling the other factors and it was not highly statistically significant $(\mathrm{p}=0.088)$. Conversely, the low BMI mother had 1.628 times higher chance of delivering LBW baby while controlling all other variables $(\mathrm{p}<$ 0.001). In addition, parity and ethnicity are also enlightening a significant effect on birth weight of babies. Prim parous mothers had 1.447 times higher chance of delivering low birth weight baby than the multiparous mothers $(\mathrm{p}=0.038)$ while controlling all other variables. These identified factors associated with low birth weight are more prevalence among teenage mothers (Low BMI: $43 \%$ in teenage mothers and $22 \%$ in the adult mothers, Prim parity: $90 \%$ in teenage mother and $38 \%$ in adult mothers). Therefore, the high prevalence of LBW among teenage mother is not completely due to the effect of age but possibly due to the risk factors, low BMI and Prim parity which are highly prevailing in the teenage mothers.

A cohort study involving all adolescent and adult pregnant women and their respective newborns delivered at the Maternity unit of the Hospital Municipal Doutor Fernando Mauro Pires da Rocha, in the city of São Paulo also showed that there is no significant difference in the prevalence of LBW between teenage and adult mothers [14]. In contrast, the study conducted in India reveals that the LBW in teenage mothers is significantly higher compare to the adult mothers [8] but in this study, the statistical tests (Chi-square and Student's $t$-test) used are not suitable to control the confounders. Therefore, this finding cannot be attributed exclusively to the age only.

The percentage of delivering premature babies among the teenage mothers (11\%) was higher than the adult mothers (6\%). The analysis revealed that that teenage mother had 1.78 times $(95 \% \mathrm{CI}, 1.18,2.68)$ higher chance of delivering a 
Table 2. Multiple Logistic Regression Model for the LBW related to Selected Biological and Socio-demographic Variables.

\begin{tabular}{|c|c|c|c|c|c|}
\hline Parameters & S.E. & Wald & df & Sig. & $\operatorname{Exp}(B)$ \\
\hline Mother's Education & & 3.669 & 4 & 0.453 & \\
\hline Not schooled & 1.350 & 0.097 & 1 & 0.756 & 1.522 \\
\hline Grade 1 - 6 & 1.233 & 0.086 & 1 & 0.769 & 0.696 \\
\hline Grade 7-GCE O/L & 1.218 & 0.122 & 1 & 0.727 & 0.654 \\
\hline GCE Advance level & 1.217 & 0.007 & 1 & 0.935 & 0.906 \\
\hline Higher education & \multicolumn{5}{|c|}{ Referral group } \\
\hline Mother's Occupation & & 2.247 & 2 & 0.325 & \\
\hline Housewife & 1.096 & 0.190 & 1 & 0.663 & 0.620 \\
\hline Government servant & 1.610 & 1.861 & 1 & 0.173 & 0.111 \\
\hline Private employee & \multicolumn{5}{|c|}{ Referral group } \\
\hline Ethnicity & & & & & \\
\hline Tamil & 0.168 & 4.772 & 1 & 0.029 & 1.443 \\
\hline Muslim & \multicolumn{5}{|c|}{ Referral group } \\
\hline Husband's Job & & 0.245 & 2 & 0.885 & \\
\hline Government Servant & 0.532 & 0.149 & 1 & 0.699 & 0.814 \\
\hline Private Sector & 0.199 & 0.147 & 1 & 0.701 & 0.926 \\
\hline Day to day worker & \multicolumn{5}{|c|}{ Referral group } \\
\hline \multicolumn{6}{|l|}{ BMI of Mother $(<12 w k)$} \\
\hline Low BMI & 0.144 & 11.456 & 1 & 0.001 & 1.628 \\
\hline Normal or High BMI & \multicolumn{5}{|c|}{ Referral group } \\
\hline Haemoglobin & & & & & \\
\hline Low $\mathrm{Hb} \%$ & 0.169 & 1.213 & 1 & 0.271 & 0.830 \\
\hline Normal Hb\% & \multicolumn{5}{|c|}{ Referral group } \\
\hline Parity & & & & & \\
\hline Primiparous & 0.178 & 4.289 & 1 & 0.038 & 1.447 \\
\hline Multiparous & \multicolumn{5}{|c|}{ Referral group } \\
\hline Age of Mother & & & & & \\
\hline Teenage & 0.164 & 2.905 & 1 & 0.088 & 1.323 \\
\hline Adult & \multicolumn{5}{|c|}{ Referral group } \\
\hline Monthly Income & & 0.725 & 2 & 0.696 & \\
\hline Up to SLR. $15,000.00$ & 0.408 & 0.017 & 1 & 0.897 & 1.054 \\
\hline More than 1SLR. 5000.00 up to SLR.30,000.00 & 0.391 & 0.060 & 1 & 0.806 & 0.908 \\
\hline More than SLR. 30,000.00 & \multicolumn{5}{|c|}{ Referral group } \\
\hline
\end{tabular}

premature baby than an adult mother while controlling the all other selected confounding variables discussed in Table 2 . All the other variables did not show 
any higher significant effect on prematurity. These findings reveal that the teenage mother had the higher risk of delivering premature babies than an adult mother due to the effect of teenage without the contribution of other factors. This finding is similar to the studies by Dias et al. (2013) in Sri Lanka [7]. Conversely, an another prospective, population-based multi-country research study done across 7 sites in six low-middle income countries (Kenya, Zambia, India, Pakistan, Guatemala and Argentina) showed that the premature deliveries and LBW are high among teenage mothers [15]. This finding is contradicting from the present study in regard to the low birth weight.

The percentage of IUGR baby was high in teenage mothers (11\%) than in adults $(8 \%)$. The binary logistic regression analysis revealed that the teenage mother had 1.5 times higher chance of delivering IUGR baby than an adult mother. (95\% CI, 1.073, 1.983). Conversely, the multiple logistic regression analysis showed that it is an almost equal chance (1.1 times) of delivering IUGR baby for teenage and adult mothers (95\% CI, 0.765, 1.61) while controlling all the selected factor in Table 2. This finding reveals that there is no difference in the risk of delivering IUGR baby between teenage and adult mothers (95\% CI, $0.765,1.61)$. Therefore, the apparent positive effect of teenage on IUGR in the binary logistic regression would be due to the confounding effect of some other associated factors with teenage which were not included in this study or the combined effect of all the associated factors including the selected control variables. This finding is par with a finding of a randomized prospective clinical study, conducted at Al-Elwiya Maternity Teaching Hospital in Baghdad [16].

Two different studies in Egypt and Iran identified contradictory results that these studies found a significant difference in IUGR between teenage and adult mothers $(\mathrm{P}<0.000)[17][18]$. But, in these studies confounding factors were not controlled. Therefore, this finding cannot be attributed to the teenage alone.

The percentage of perinatal complications was less among teenage mothers (12\%) than the adult mothers (16\%) that the chances of developing perinatal complications among teenage mothers were 0.725 times less compare to the adult mothers $(95 \%$ CI, $0.559,0.940)$. This statistical significance had lost in the multiple logistic regression model and the chance of perinatal complication became almost equal to both age groups. The Normal or higher BMI mothers had 2.153 times higher chance for developing perinatal complications compare to low BMI mothers while controlling all other variables discussed in Table 2 (95\% CI, 1.506, 3.076). This scenario explains that the apparent low risk of perinatal complications in teenage mothers might be due to the effect of teenage that associated with BMI. Dias et al. (2013) also found that the intrauterine death rate and early neonatal death rates were not significantly higher among teenagers compared to the adult age group of 20 - 34 years [7].

In terms of mode of delivery, the percentage of LSCS (Emergency \& Elective) was low among the teenage mothers (10\%) compare to the adult mothers (14\%). The binary logistic regression analysis revealed that the chance of LSCS among 
teenage mothers was 0.677 times compare to the adult mothers. (95\% CI, 0.51 , 0.897) This statistical significance had lost in the multiple logistic regression model and the chance of LSCS became almost equal to both age groups whereas the normal or high BMI mothers had 2.379 times higher chance for undergoing LSCS than a low BMI mother while controlling all other variables. (95\% CI, $1.654,3.564)$.

\section{Conclusion}

Based on this study, the premature birth was the only perinatal outcome directly related to teenage mothers $(\mathrm{P}<0.001)$. Prematurity is the well-known factor for neonatal morbidity and mortality. This study revealed that the teenage pregnancy had a higher chance of premature delivery. All other negative pregnancy outcomes were associated with teenage pregnancy, and were caused by other factors which are prevailing in higher percentage among teenagers. The higher prevalence rate of LBW among the teenage mothers was due to the presence of high percentage of low BMI and primiparous mothers in the teenage group. No differences in occurrence of IUGR, perinatal complications and LSCS were observed between teenage and adult mothers. The low BMI shows the strong positive association with low birth weight and high BMI shows strong positive association with perinatal complication and LSCS. If there is a way to control the risk of premature birth, teenage pregnancy cannot be a big issue for the mothers with better BMI. Early pregnancies are associated with higher overall fertility rates. Reducing the number of early pregnancies and promoting adequate birth spacing contribute to lower total fertility rates. On the other hand, lower total fertility rates are associated with better health status of children. Therefore, the policy makers have to consider all these facts in health related issues. One main limitation of this study is, all the samples for this study were selected from one district of Sri Lanka and therefore results of this study can't be easily generalized to the whole country.

\section{References}

[1] Mayor, S. (2004) Pregnancy and Childbirth Are Leading Causes of Death in Teenage Girls in Developing Countries. BMJ, 328, 1152.

[2] World Health Organization (2004) Adolescent Pregnancy Issues in Adolescent Health and Development. WHO Discussion Papers on Adolescence, 1-92.

[3] UNICHEF (2008) Young People and Family Planning: Teenage Pregnancy. Fact Sheet: Plan You Family Plan Your Future.

https://www.unicef.org/malaysia/Teenage_Pregnancies_-_Overview.pdf

[4] Hala, A.F.A. and Rehab, A.A. (2016) Effect of an Educational Program about Newborn Care on Practice and Confidence of Pregnant Teen Mothers. IOSR Journal of Nursing and Health Science, 5, 38-46.

[5] Hoffman, D. (2008) Kids Having Kids: Economic Costs and Social Consequences of Teen Pregnancy. The Urban Institute Press, Washington, DC, 259-294.

[6] John, S.S. and Andrea, J.M. (2010) Teen Fertility in Transition: Recent and Historic 
Trends in the United States. Annual Review of Public Health, 31, 371-383. https://doi.org/10.1146/annurev.publhealth.29.020907.090830

[7] Dias, T., Wijesinghe, E., Abeykoon, S., Ganeshamoorthy, P., Kumarasiri, S., Kodithuwakku, M., Gunewardena, C. and Padeniya, T. (2013) Pregnancy Outcome in Extremes of Reproductive Age at a Tertiary Care Hospital. Sri Lanka Journal of Obstetrics and Gynecology, 35, 77-79.

[8] Mukhopadhyay, P., Chaudhuri, R.N. and Paul, B. (2010) Hospital-Based Perinatal Outcomes and Complications in Teenage Pregnancy in India. Journal of Health Population and Nutrition, 28, 494-500. https://doi.org/10.3329/jhpn.v28i5.6158

[9] Dutta, I. and Joshi, P. (2013) Maternal and Perinatal Outcome in Teenage vs. Vicenarian Primigravidae-A Clinical Study. Journal of Clinical and Diagnostic Research, 7, 2881-2884.

[10] Gunewardene, I.M.R. and Deeyagaha, W.R.P.K. (2005) Adverse Effects of Teenage Pregnancy. The Ceylon Medical Journal, 50, 116-120.

[11] Sulaiman, S., Othman, S., Razali, N. and Hassan, J. (2013) Obstetric and Perinatal Outcome in Teenage Pregnancies. South African Journal of Obstetrics and Gynaecology, 19, 74-77. https://doi.org/10.7196/sajog.679

[12] Fleming, N., Osborne, C., Biederman, S., Yaseen, A.S., Jessica, D., White, R.R. and Walker, M. (2013) Adolescent Pregnancy Outcomes in the Province of Ontario: A Cohort Study. Journal of Obstetrics and Gynacology Canada, 35, 234-245. https://doi.org/10.1016/S1701-2163(15)30995-6

[13] Ganchimeg, T., Ota, E., Morisaki, N., Laopaiboon, M. and Lumbiganon, P. (2014) Pregnancy and Childbirth Outcomes among Adolescent Mothers: A World Health Organization Multicounty Study. BJOG: An International Journal of Obstetrics \& Gynecology, 121, 40-48. https://doi.org/10.1111/1471-0528.12630

[14] Perez Neto, M.I. and Segre, C.A. (2012) Comparative Analysis of Gestations and Frequency of Prematurity and Low Birth Weight among Children of Adolescent and Adult Mothers. Einstein, 10, 271-277. https://doi.org/10.1590/S1679-45082012000300003

[15] Althabe, F., Moore, J.L., Gibbons, L., Berrueta, M., Goudar, S.S., Chomba, E., et al. (2015) Adverse Maternal and Perinatal Outcomes in Adolescent Pregnancies: The Global Network's Maternal Newborn Health Registry Study. Reproductive Health, 12, 2-8. https://doi.org/10.1186/1742-4755-12-S2-S8

[16] Najim, T., Ghathwan, K.I., Alnakkash, U.M. and Abdelraheem, Y. (2015) The Impact of Teenage Pregnancy on Maternal, Fetal and Neonatal Outcomes. International Journal of Scientific Research in Knowledge, 3, 0106-0113. https://doi.org/10.12983/ijsrk-2015-p0106-0113

[17] Edessy, M., Gaber, M. and Maher, A. (2014) Teenage Pregnancy and Fetal Outcome. American Journal of Research Communication, 2, 169-175.

[18] Nili, F., Rahmati, M.R. and Sharifi, S.M. (2002) Maternal and Neonatal Outcome in Teenage Pregnancy in Tehran Valiasr Hospital. Acta Medica Iranica, 40, 55-59. 
Submit or recommend next manuscript to OALib Journal and we will provide best service for you:

- Publication frequency: Monthly

- 9 subject areas of science, technology and medicine

- Fair and rigorous peer-review system

- Fast publication process

- Article promotion in various social networking sites (LinkedIn, Facebook, Twitter, etc.)

- Maximum dissemination of your research work

Submit Your Paper Online: Click Here to Submit

Or Contact service@oalib.com 